\title{
Semelhanças e diferenças entre duas sentenças exclamativas do português brasileiro
}

Marcelo Amorim Sibaldo ${ }^{a}$

\begin{abstract}
Resumo
O presente trabalho objetiva, no plano descritivo, observar o padrão sintático-semântico de duas estruturas exclamativas pouco estudadas do português brasileiro e, por meio de de alguns testes, verificar quais as diferenças e semelhanças entre elas. Já no plano teórico, a partir dos resultados dos testes aplicados, verificamos como essas estruturas são derivadas, adotando como quadro conceitual a Gramática Gerativa, no modelo do Programa Minimalista (CHOMSKY, 2001 e sequência). Após apresentação, discussão e análise teórica dos dados dessas estruturas exclamativas, atestamos que elas possuem estruturas distintas: uma delas se comporta como um Sintagma de Tempo (TP) e a outra como um Sintagma Complementizador (CP).
\end{abstract}

Palavras-chave: Sintaxe; exclamativas; português brasileiro. 


\section{Introdução}

No português brasileiro (doravante PB), há uma construção pouco estudada, que nomearemos aqui de Small Clause Livre (cf. KATO, 1988), que é caracterizada pela justaposição de um predicado e seu sujeito, nessa ordem, sem verbo ou morfologia de tempo na superfície, como em (1) abaixo:

(1) a. Muito linda essa bolsa!

b. Uma droga aquela aula!

Além dessas estruturas exclamativas, podemos ter também contruções bem semelhantes a (1), diferindo dessas apenas em respeito ao uso do primeiro elemento do predicado, em que temos, no lugar de um intensificador Muito (cf. (1a)) ou um artigo indefinido uma (cf. (1b)), a partícula "que", como em (2) abaixo:

(2) a. Que linda essa bolsa!

b. Que droga aquela aula!

Chamaremos essas últimas estruturas de que-Small Clause Livre.

Como podemos ver, na superfície, a diferença entre (1) e (2) parece estar somente na troca dos primeiros elementos do predicado, "muito" e "um" nas Small Clauses Livres (doravante SCLs) e "que" nas que-Small Clauses Livres (doravante queSCLs). É importante destacar que esses elementos parecem estar em distribuição complementar, uma vez que as estruturas abaixo não são possíveis no $\mathrm{PB}^{1}$ :

(3) a. *Que muito linda essa bolsa! a'. *Muito que linda essa bolsa!

b. *Que uma droga aquela aula! b'. *Uma que droga aquela aula!

Dada a apresentação dos dados acima, a questão que este artigo buscará responder é: qual a estrutura sintática dessas estruturas, uma vez que ambas parecem ser menores que uma oração por lhes faltar o verbo? Assim, o objetivo do presente artigo é descrever e comparar essas duas estruturas exclamativas do $\mathrm{PB}$, tentando traçar uma estrutura sintática subjacente a essas construções.

No que diz respeito ao embasamento teórico, lançaremos

${ }^{1} \mathrm{O}$ asterisco antes das agramaticalidade. mão dos pressupostos teóricos do Programa Minimalista (cf. 
CHOMSKY, 2001 e sequência), bem como da ideia de Small Clause (doravante SC), como delineada em Den Dikken (2006), em que é proposta uma estrutura assimétrica para a SC, nesse sentido, a predicação envolve uma estrutura assimétrica incluindo o sujeito, seu predicado e um elemento funcional (o RELATOR), que media a relação uniformemente assimétrica e não-direcional do predicado e do seu sujeito. Iremos lançar mão, também da ideia de Extensão de Fase (cf. DEN DIKKEN, 2006, 2007), em que o alçamento do núcleo de uma fase para o núcleo mais próximo do sintagma acima desta fase estende a fase para este núcleo mais próximo.

Dessa forma, para se fazer a discussão pretendida, este artigo está dividido da seguinte forma: na primeira seção, faremos algumas observações sobre sentenças exclamativas e mostraremos alguns testes para as estruturas estudadas; na segunda seção, apresentaremos algumas propriedades sintático-semânticas do sujeito e predicados dessas estruturas; na terceira seção, aplicaremos alguns diagnósticos sintáticos em ambas as estruturas (encaixamento, advérbios, negação etc.), a fim de delinear semelhanças e diferenças de suas estruturas sintáticas; na quarta seção, mostraremos como funciona a derivação de ambas as estruturas, levando em consideração o resultados dos testes feitos anteriormente e o arcabouço teórico adotado; por fim, nas considerações finais, retomaremos os principais pontos discutidos neste artigo.

\section{1. (Que-)SCLs são sentenças exclamativas}

Estudos feitos em sentenças exclamativas são escassos, principalmente, quando comparamos com os estudos feitos em sentenças interrogativas. Quando pensamos em território nacional, vemos que estudos sobre exclamativas são ainda mais raros. Assim, para fazermos um exercício de reconhecimento desse tipo de sentença, antes de tentarmos analisar e apresentar uma estrutura para as (que-)SCLs², é importante arrolarmos alguns testes sintáticos disponíveis na literatura

${ }^{2}$ Daqui por diante, quando usarmos (que-) SCLs, estaremos falando tanto das SCLs quanto das que-SCLs. para reconhecermos uma sentença exclamativa, inclusive para incluirmos as (que-)SCLs no rol desse tipo de sentença.

As características principais das sentenças exclamativas compreendem (i) a implicatura escalar, (ii) o uso na relação 
pergunta-resposta, e (iii) a factividade (cf. ZANUTTINI \& PORTNER, 2003).

A primeira delas diz respeito à implicatura escalar, no sentido de que as exclamativas estão relacionadas, de alguma forma, à surpresa ou a algo digno de ser notado. Desse modo, as exclamativas denotam na sua proposição alguma extremidade em alguma escala. Por exemplo, em Que feio o seu sapato!, há uma indicação de que o grau de "feiura" do sapato é maior do que o esperado, por isso foi digno de ser apontado. Além disso, este adjetivo pode ser graduável com intensificadores, como muito, por exemplo. Como veremos na próxima seção deste trabalho, as (que-)SCLs devem sempre ter associadas a elas um adjetivo/ DP avaliativo que possa ser graduável como predicado, como mostrado no contraste abaixo:

(4) a. Muito/ Que lindo o meu sobrinho!

b. *Muito/ Que russa aquela Vodka!

Vemos em (4) que não há como um predicado que não possa ser graduável fazer parte das (que-)SCLs.

Já a segunda característica das exclamativas diz respeito ao fato de que as exclamativas não podem entrar em pares de pergunta-resposta, uma vez que elas não podem ser respondidas, como as sentenças interrogativas ${ }^{3}$ :

(5) a. A: How tall is he? B: Seven feet.

(ZANUTTINI \& PORTNER, 2003, p. 27)

b. A: How very tall he is! B: *Seven feet.

(6) a. A: Muito inteligente a Maria! B: *Sim.

b. A: Que linda a sua namorada! B: *Claro! ${ }^{3}$ Segundo Elliott (1974),
o uso de very "muito" nessas estruturas força a sentença a ser interpretada como uma exclamativa, o que, mais uma vez, desemboca na questão da implicatura escalar.
A terceira e última característica arrolada por Zanuttini e Portner (2003) para se verificar uma exclamativa tem a ver com o fato de essas estruturas poderem ser encaixadas somente em predicados factivos, como o verbo to know "saber", por exemplo (dado de ZANUTTINI \& PORTNER, 2003, p. 9, ex. (12)):

(7) Mary knows/*thinks/*wonders how very cute he is.

Mary sabel *acha/ *pensa que muito bonito ele é

Entretanto, como vemos a seguir, as (que-)SCLs não podem ser encaixadas em predicados factivos: 
(8) a. * Os professores sabem excelentes esses alunos!

b. *Os moleques sabem muito gostoso esse doce!

c. *O Pedro sabe que luxo essa casa!

Essa comportamento das (que-)SCLs, na verdade, é esperado, uma vez que, como o próprio nomes delas sugere, elas são "livres", ou seja, são estruturas raízes.

Assim, nesta seção, testamos, a partir das características elencadas por Zanuttini e Portner (2003), se as (que-)SCLs podem ser enquadradas como sentenças exclamativas e verificamos que, dos três testes dados, essas estruturas foram "aprovadas" em dois, sendo justificada a "falha" no teste de factividade pelo fato, a ser apresentado nas seções 3 e 4 , de que as (que-)SCLs são estruturas raízes, que não podem ser encaixadas em nenhum tipo de verbo.

\section{Restrições sintático-semânticas das (que-)SCLs}

Nesta seção, iremos mostrar algumas semelhanças e diferenças entre as SCLs e as que-SCLs em relação a alguns aspectos sintáticos e semânticos de seus sujeitos e predicados. Para começar, veremos a restrição sobre a ordem desses elementos.

2.1. Restrição sobre a ordenação de sujeito e predicado

Como vemos abaixo, tanto as SCLs quanto as que-SCLs têm a sua ordenação fixada, ou seja, a ordem permitida em ambas as estruturas é predicado e sujeito:
(9) a. Muita linda essa bolsa!
a'. *Essa bolsa muita linda!
b. Uma droga aquela aula!
$\mathrm{b}^{\prime}$. *Aquela aula uma droga!
c. Que linda essa bolsa!
c. *Essa bolsa que linda!
d. Que droga aquela aula!
d'. *Aquela aula que droga!

Como visto em (9), a ordem dos constituintes das (que-) SCLs é fixa, uma vez que o fronteamento do sujeito é excluído.

2.2. Restrição sobre a semântica do sujeito

Em relação à semântica do sujeito dessas construções, percebemos em (10) que, em ambas, o sujeito deve ser específico 
e saliente no discurso, não podendo ser indefinido, singular/ plural nu, conter item de polaridade negativa:
(10) a. Muito linda essa bolsa!
a'. Que linda essa bolsa!
b. *Muito linda uma bolsa!
b'. *Que linda uma bolsa!
c. *Muito linda(s) bolsa(s)!
c'. *Que linda(s) bolsa(s)!
d. *Muito linda nenhuma bolsa!
d'. *Que linda nenhuma bolsa!

Vemos na comparação entre as estruturas acima que há uma semelhança entre as construções e apenas sintagmas nominais fortemente referenciais e específicos podem configurar como sujeito das (que-)SCLs.

\subsection{Restrição sobre a semântica do predicado}

Sobre os predicados dessas estruturas, temos duas observações a fazer: a primeira delas diz respeito ao tipo de constituinte que pode atuar como núcleo do predicado. Como podemos ver abaixo, os únicos constituintes que aparecem nas (que-) SCLs são adjetivos e alguns sintagmas nominais:
(11) a. (Muito) linda essa bolsa! ${ }^{4}$
a'. Que linda essa bolsa!
b. Um luxo a sua bolsa!
b'. Que luxo a sua bolsa!
c. *Um professor aquele cara!
c'. *?Que professor aquele cara!
d. *Trabalhando aquele cara!
d'. *Que trabalhando aquele cara!
e. *Em NY o Pedro!
e'. *Que (em) NY o Pedro!
f. *Mal o Pedro!
f'. *Que mal o Pedro!

Note que, nas SCLs, o predicado pode ser um sintagma adjetival (11a) ou um sintagma nominal que nomearemos aqui como sintagma nominal avaliativo (11b), que difere dos sintagmas nominais "comuns" (11c), que não são aceitos nessas estruturas. Não são aceitos também sintagmas verbais (11d), preposicionais (11e) ou adverbiais (11f). Semelhantemente, nas que-SCLs, podemos encontrar, como predicados, sintagmas adjetivais (11a') e nominais avaliativos $\left(11 b^{\prime}\right)$. Entretanto, em (11c'), observamos que há uma possível aceitação de sintagmas nominais "comuns" por alguns falantes, uma vez

${ }^{4}$ Quando o predicado das SCLs é um sintagma adjetival, a inclusão do intensificador parece ser opcional. que a partícula "que" parece, em algum grau, avaliar (ou qualificar) o núcleo do sintagma nominal. Note que, quando acrescido de um adjetivo avaliativo, a estrutura melhora: "Que excelente professor aquele cara!"| "Que péssimo professor aquele 
cara!". Igualmente às SCLs, as que-SCLs também não aceitam sintagmas verbais $\left(11 d^{\prime}\right)$, preposicionais $\left(11 e^{\prime}\right)$ ou adverbiais (11f') como predicados.

Ainda em relação à semântica do predicado dessas estruturas, podemos perceber, mais uma vez, uma semelhança, já que, em ambas, o núcleo do predicado, quando adjetival, deve ser graduável, intensificável, avaliativo e, ainda, de nível individual, como nos mostra os dados abaixo:
a. *Bêbado o João!
a'. *Que bêbado o João!
b. *Grávida esse menina!
b'. *Que grávida esse menina!

Por conta desses fatos, assumiremos que o predicado só poder ser selecionado para estar nas (que-)SCLs, se ele for um DegP (Sintagma de Grau, do inglês Degree Phrase). Como sabemos, as (que-)SCLs não podem ir com predicados que não contenham algum grau, por outro lado, os DPs "avaliativos" são estruturas cujo núcleo nominal $\mathrm{N}$, normalmente, deriva adjetivos avaliativos (um luxo > muito luxuoso, por exemplo) e, como visto acima, tanto tais DPs quanto tais adjetivos, de algum modo, capturam a ideia de grau ${ }^{5}$.

Entretanto, é importante notar que a máxima aqui tem a ver com a avaliatividade do predicado, uma vez que em (12), caso adicionemos um adjetivo avaliativo, a estrutura fica gramatical, como vemos em (13) abaixo:
(13) a. Bêbado chato o João!
a'. Que bêbado chato o João!
b. Grávida feia esse menina!
$b^{\prime}$. Que grávida feia esse menina!

Assim, o predicado das (que-)SCLs do PB devem descrever uma impressão, uma opinião pessoal do falante, que menciona algo de surpreendente, surpresa, ou algo fora do comum, como é inerente às sentenças exclamativas (cf. ZANUTTINI; PORTNER, 2003). O predicado individual deve, então, ser uma apreciação e não pode ser uma expressão referencial.

${ }^{5}$ Além do mais, os estudos recentes indicam o fato de que as sentenças exclamativas são, na verdade, construções de grau (cf. CASTROVIEJO, 2007; GUTIÉRREZ-REXACH, 2008).

\subsection{Restrição sobre a semântica do tempo}

Em ambas as estruturas não temos morfologia visível de tempo na superfície, mas podemos subentender o tempo, no contexto out-of-the-blue, como sendo o presente: 
(14) a. Muito linda essa bolsa!

a'. Que linda essa bolsa!

"Essa bolsa é/ *era/ *será muito linda!"

b. Uma droga aquela aula!

b'. Que droga aquela aula!

"Aquela aula é/ *era/ "será uma droga!"

Percebemos ainda que o predicado é interpretado como sendo estativo, no sentido em que o tempo é "entendido" como a forma do presente do indicativo e o predicado não pode ser entendido como (nem pode ser (cf. (11d)) um verbo na forma gerundiva, o que corrobora o fato de o predicado das (que-) SCLs serem sempre estativos:

(15) a. Muito linda essa bolsa!

a'. Que linda essa bolsa!

“*Essa bolsa está sendo muito linda!"

b. Uma droga aquela aula!

$b^{\prime}$. Que droga aquela aula!

“*Aquela aula está sendo uma droga!”

Resumindo, vimos nesta seção que ambas as estruturas compartilham características semelhantes no que concerne à ordem, ao sujeito, ao predicado e ao tempo (não morfológico) dessas estruturas.

\section{Testes sintáticos para as (que-)SCLs}

Nesta seção, iremos fazer alguns testes sintáticos tanto com as SCLs quanto com as que-SCLs, a fim de delinearmos uma estrutura sintática para essas estruturas do PB.

3.1. Onde estão o sujeito e o predicado das (que-)SCL?

Verificaremos aqui se as (que-)SCLs do PB são o resultado da adjunção do sujeito à direita ou do alçamento do predicado para uma posição-A'. Assim, para responder à questão colocada acima, lançaremos mão, primeiramente, do teste com advérbios de tempo e Sintagmas Preposicionais (i. e., PPs) locativos, pois, como é sabido, na teoria gerativa, advérbios de tempo e PPs locativos marcam o limite de uma sentença nuclear, sendo assim, o que vier após estes elementos é tomado como elementos que se encontram numa posição-A'. Tendo isto em mente, o contraste entre os dados em (16) e (17) abaixo, parece corroborar a ideia de que as (que-)SCLs não são fruto de deslocamento à direita do sujeito, visto que nem o advérbio 
de tempo nem o locativo podem intervir entre o predicado e o sujeito das (que-)SCLs:

(16) a. *Muito/ Que lindas na igreja/ ontem as flores!

b. *Bonito/ Que na festa/ ontem o seu vestido!

(17) a. Muito/ Que lindas as flores na igreja/ontem!

b. (Que) Bonito seu vestido na festa/ontem!

De mais a mais, quantificadores podem ocupar a posição de sujeito das (que-)SCLs e, como se sabe, quantificadores não podem ocupar uma posição A' (cf. RIZZI, 1997, entre inúmeros trabalhos) ${ }^{6}$ :

(18) a. Um/ Que amor cada um de vocês!

b. Muito/ Que lindos todos esses seus sapatos!

Dada a argumentação acima, é tentador afirmar que as (que-)SCLs do PB, na verdade, são resultados de movimento- $\mathrm{A}^{\prime}$ do predicado sobre o seu sujeito. Entretanto, como (19) abaixo nos mostra, itens de polaridade negativa (NPIs) são aceitos na posição de predicado das SCLs e, igualmente aos quantificadores, NPIs, geralmente, não são aceitos em posição-A'.

${ }^{6}$ Alguém poderia nos chamar atenção para o fato de que quantificadores negativos não são aceitos na posição de sujeito das SCLs, como nos mostram os dados em : (i) a. *Muito linda ninguém! $b$. *Excelente nenhuma sopa daquelas! c. *Uma merda nada! Ora, de acordo com a literatura, esses itens são considerados como indefinidos não-específicos e um constituinte com essa característica não pode aparecer na posição de sujeito das SCLs, como vimos anteriormente. De mais a mais, a nosso ver, este fenômeno parece, ainda, ter alguma relação com a proibição da negação das sentenças exclamativas, pois, de acordo com Bartra \& Villalba (2006, p. 3), "negation is generally forbidden in exclamatives".

(19) a. Nem um pouco bonita a Maria!

b. Nada gostosa a sua irmã!

O teste em relação aos NPIs fica comprometido com as que-SCLs, pois, como semelhantemente ao que vimos em (3), esses elementos também parecem estar em distribuição complementar com a partícula "que", como observado em (20) abaixo:

(20) a. ( ${ }^{*}$ Que) nem ( ${ }^{*}$ que) pouco bonita a Maria!

b. ( ${ }^{*}$ Que) nada ( ${ }^{*}$ que) gostosa a sua irmã!

Isso acontece, porque os NPIs, assim como o "que", também intensificam de algum modo o predicado dessas estruturas. Entretanto, assumiremos, com base em (21), que o predicado das que-SCLs estão numa posição- $\mathrm{A}^{\prime}$ diferentemente do predicado das SCLs que estão, assumiremos, numa posição-A. 
(21) a. A Maria não é nem um pouco bonita/ é muito bonita/ * é que bonita!

b. A sua irmã não é nada gostosa/ é muito gostosa/ * é que gostosa!

A ideia por trás de (21) é que um constituinte contendo a partícula "que" + adjetivo não pode ficar numa posição-A, tendo sempre que ser alçado para uma posição- $A^{\prime}$ por conter o traço [+wh], que deve ser checado com a sua subida para CP.

Resumindo, como visto aqui, os advérbios temporais e os PPs locativos não podem intervir entre o predicado e o sujeito das (que-)SCLs, bem como, DPs com quantificadores podem atuar como sujeitos das (que-)SCLs, que se assemelham em todos esses aspectos. Desse modo, o que os dados apresentados aqui sugerem é que o DP sujeito das (que-)SCLs do PB estão numa posição-A e não numa posição-A'. Porém detectamos uma diferença entre essas estruturas em relação ao seu predicado: nas SCLs, verificamos que há a possibilidade de o predicado ir com NPIs, o que corrobora a assunção de eles estarem numa posição-A; já para as que-SCLS, verificamos que um predicado contendo a partícula "que"+adjetivo não pode permanecer numa posição-A, o que nos permite dizer que o predicado das que-SCLs esteja numa posição-A'.

\subsection{As (que-)SCLs têm o caráter sentencial ou verbal?}

Já que as (que-)SCLs do PB se mostram, superficialmente, menores que uma sentença ordinária, porém, com a leitura subjacente de uma sentença copular do $\mathrm{PB}$, cumpre arrolar a seguinte questão: as (que-)SCL têm um status nominal ou um status sentencial? Um teste bastante utilizado na literatura para saber se uma determinada estrutura é um nome ou uma sentença é o teste de clivagem (cf. BARTRA \& VILLALBA, 2006), pois, no $\mathrm{PB}$, apenas nominais e CPs completos podem ser clivados.

Abaixo, podemos ver que construções com inversão

${ }^{7}$ Tomamos esse tipo de DP por se assemelhar às (que-)SCLs, uma vez que o adjetivo-"predicado" dessas estruturas está à frente do nome-"sujeito".
Sintagma de Determinante (i. e. DP) predicado (cf. DEN DIKKEN, 1998 $)^{7}$ tem característica, claro, de um nominal e, como um nominal, ele pode ser clivado (cf. (22)), por outro modo, as (que-)SCLs não podem ser clivadas (cf. (23)), o que parece sugerir que as SCLs não têm um status de um nominal, mas sim características de um item sentencial. 
(22) a. Foi $\left[_{D P}\right.$ o idiota do marinheiro] que o Pedro viu.

b. Foi $\left[_{\mathrm{DP}}\right.$ aquele babaca do policial] que a Maria xingou.

(23) a. *Foi [(que) bonita a sua roupa] que eu achei.

b. *Foi [que/ uma merda aquele filme] que eu considerei.

Assim, teremos, agora, de nos perguntar em que sentido as (que-)SCLs têm o status de um sentencial. Trataremos, a seguir, de verificar o tamanho desses tipos de sentenças, i. e., quais categorias funcionais formam as SCLs (se elas possuírem) e qual a sua estrutura interna.

\subsection{Onde estão as (que-)SCLs?}

Outro teste a ser explorado para diagnosticar a posição dos constituintes das (que-)SCLs é a distribuição dos advérbios de VP naquelas estruturas. Como se sabe, advérbios de VP, como sempre, por exemplo, são aqueles em que são assumidos estarem numa posição de adjunção ao $\mathrm{VP}^{8}$, ou seja, abaixo de TP. Sendo assim, o uso desses advérbios nas (que-)SCLs pode ser muito útil para testar a posição exata do predicado das SCLs:
(24) a. Sempre bonita a sua roupa!
(25) a. *Bonita sempre a sua roupa.
b. Sempre muito chata essa aula!
b. *Muito chata sempre essa aula.

Como o contraste observado entre (24) e (25) sugere, o predicado das SCLs não parece ter sido movido para uma posição acima da Small Clause, uma vez que a estrutura em que o advérbio se encontra entre o predicado e o sujeito é agramatical, como observado em (25), em detrimento da gramaticalidade das estruturas com o advérbio na posição inicial, como mostrado em (24). Esse resultado difere das queSCLs, como nos mostram as estruturas abaixo:

(26) a. *Sempre que bonita a sua roupa! (27) a. *Que bonita sempre a sua roupa.

b. *Sempre que chata essa aula! b. *Que chata sempre essa aula.

${ }^{8}$ Como tratamos de SCs aqui, assumiremos que estes advérbios estão adjungidos à SC.
A assimetria entre (24) e (25) não aparece em (26)-(27). Neste caso, ambos os exemplos são agramaticais. (26) parece sugerir que o predicado não está abaixo da SC; já (27) sugere é que o sujeito também não está abaixo da SC, i. e., não está in situ. Dessa forma, diferentemente das SCLs, em que tanto o 
sujeito quanto o predicado parecem estar na SC, nas que-SCLs, temos o sujeito e o predicado acima da SC.

\subsection{Existem projeções funcionais nas (que-)SCLs?}

Cardinaletti \& Guasti (1995) observam que, diferentemente das Full Clauses, as Small Clauses não apresentam uma projeção de tempo em sua estrutura. As autoras assumem com Sportiche (1988) que os advérbios se adjungem à categoria que eles modificam e que advérbios de tempo são licenciados por uma projeção de tempo (cf. MARANTZ, 1984), desse modo, elas argumentam que, quando não há uma projeção do tipo TP numa determinada sentença, a modificação temporal por esses advérbios se torna impossível. Isso é exemplificado pelas estruturas do italiano, em (28) e do PB, em (29):

(28) a. Oggi ritengo che Gianni era malato, ieri.

Hoje acredito que Gianni estava doente ontem

b. *Oggi ritengo Gianni malato, ieri.

Hoje acredito Gianni doente ontem

(CARDINALETTI \& GUASTI, 1995, p. 14, ex. (14))

(29) a. Hoje eu acho que o João estava bêbado ontem.

b. *Hoje eu acho o João bêbado ontem.

Ainda de acordo com Cardinaletti \& Guasti (1995), os dois advérbios temporais conflitantes, oggi "hoje" e ieri "ontem", pressupõem a presença de duas projeções TPs. A agramaticalidade de (28b) e (29b) seria, então, explicada pelo fato de a projeção TP da SC complemento não ter sido detonada.

Além dos advérbios de tempo, as autoras também tomam a negação como um teste para saber se as SCs têm TP em sua estrutura. Elas seguem a linha de raciocínio desenvolvida por Zanuttini (1991), que correlaciona negação sentencial e tempo, ou seja, quando há a presença de uma negação, uma projeção de tempo deve ser assumida. De acordo com os dados abaixo, em que a negação sentencial não é atestada nas SCs, o que se depreende, mais uma vez, é que não há uma presença de nenhum TP nas SCs:

(30) a. Penso che Gianni non sai mai contento.

"Eu acho que o João não está feliz nunca." 
b. *Ritengo Gianni non mai contento.

Considero Gianni não muito contente

(CARDINALETTI \& GUASTI, 1995, p. 13, exs. (10a) e (11a))

(31) a. Eu acho que a Maria não está triste.

b. *Eu acho a Maria não triste.

Dada a discussão acima e tendo em vista que as (que-) SCLs do PB têm uma característica de sentencial, é relevante perguntar se estas estruturas, diferentemente das SCs comuns, têm uma projeção do nível de TP em sua estrutura interna. Seguindo a linha de raciocínio desenvolvida por Cardinaletti \& Guasti (1995), faremos os mesmos testes com advérbios de tempo e negação nas (que-)SCLs do PB, para evidenciar ou não a projeção TP na sua estrutura interna.

Num primeiro momento, faremos o teste com advérbios de tempo:

(32) a. Bonita a sua roupa ontem!

b. Que lindo o dia hoje!

Os dados acima apontam para o fato de que as (que-) SCLs, apesar de não mostrarem morfologia de tempo visível, suportam a adição de um advérbio de tempo, o que corrobora a ideia de que as (que-)SCLs do PB, diferentemente das SCs comuns, têm uma projeção funcional TP em sua estrutura.

Em relação ao outro teste que Cardinaletti \& Guasti (1995) apontam para saber se as SCs têm TP, nomeadamente, ao teste da negação, podemos observar abaixo que as SCLs não podem ser negadas, como mostra (33):

(33) (*Não) (que) bonita (*não) a Maria (*não)!

Porém, essa característica, na verdade, não surpreende, uma vez que a exclamação não pode ser negada ${ }^{9}$ (ZANUTTINI \& PORTNER, 2003; VILLALBA, 2004; BARTRA \& VILLALBA, 2006). Porém, uma evidência que pode ser dada, no sentido

${ }^{9}$ Salvo alguns casos de negação expletiva e outros de negação padrão, que requer contextos apropriados, ver Villalba (2004). de que a negação pode ocorrer nas SCLs, é o caso do exemplo (19), repetido abaixo como (34):

(34) a. Nem um pouco bonita a Maria!

b. Nada gostosa a sua irmã! 
Para que as sentenças acima se tornem gramaticais numa sentença canônica com cópula, a presença da primeira negação é obrigatória, como pode ser visto abaixo ${ }^{10}$ :

(35) a. A Maria *(não) é nem um pouco bonita!

b. A sua irmã *(não) é nada gostosa!

Ora, se um item de polaridade negativa tem que, por definição, ter um outro elemento para ser licenciado e para que a polarização ocorra, achamos razoável assumir que há uma negação subjacente licenciando os NPIs nas derivações em (34), i. e., há TP na estrutura.

Como pudemos ver na seção 2.1., a ordem canônica de uma (que-)SCL é a ordem Predicado + Sujeito, assim, a ordem Sujeito + Predicado é sempre descartada. Além disso, como vimos na seção 1, as exclamativas (em especial, as (que-)SCLs) não podem ser encaixadas. Entretanto, é curioso perceber que, em verbos de Marcação Excepcional de Caso $(\mathrm{ECM})^{11}$, algumas estruturas parecidas com as SCLs podem ser encaixadas e em ambas as ordens dos constituintes:

(36) a. Eu achei [lindo o dia]/ [o dia lindo].

b. A Maria achou [muito bonita a sua roupa]/ [a sua roupa muito bonita].

Porém, apesar de as estruturas que vêm logo após os verbos ECM de (36) serem superficialmente idênticas às SCLs (na ordem Pred+Suj), tais itens pós-verbo ECM acima são apenas uma SC complemento comum e não uma SCL "genuína". Essa afirmação pode ser corroborada pelo fato de que, como discutido acima, as SCs encaixadas nas construções ECM não têm uma projeção TP, como nos mostram os dados abaixo:

${ }^{10}$ Como vimos anteriormente, uma estrutura com "que" seria agramatical nesse contexto, pois contituintes com "que" são possíveis somente em prosição $\mathrm{A}^{\prime}$, igualmente aos dados que seguem em (36).

${ }^{11}$ Kato (1988) foi a primeira pessoa, tanto quanto saibamos, a apontar esse fato.
(37) a. Hoje eu achei [lindo o dia] *ontem.

b. Hoje a Maria achou [bonita a sua roupa] *ntem.

A nosso ver, os dados acima são argumentos fortes para a assunção de que SCLs são TPs raízes, ou seja, as Small Clauses Livres são, como o próprio nome diz, "livres" e não podem ser encaixadas. Ora, como vimos anteriormente, SCs não podem ter $\mathrm{T}(\mathrm{empo})$ associado à sua projeção. Por outro lado, circundando o exemplo (32), apontamos para o fato de que, ao contrário das SCs comuns, (que-)SCLs podem ter um 
advérbio de tempo adjungido à sua estrutura, seguindo a linha de raciocínio desenvolvida por Cardinaletti \& Guasti (1995), Marantz (1984), Zanuttini (1991), entre muitos outros, logo, podem ter TPs sem CPs, como também corroborou o fato de poder haver uma negação não realizada foneticamente (cf. (34)). Dessa forma, depreendemos que o que está encaixado sob o verbo ECM em (36) é, na verdade, SC e não SCL.

Se a análise aqui empreendida for levada em consideração, poderemos explicar facilmente o porquê de poder haver a alternância Predicado-Sujeito/ Sujeito-Predicado, em (36): as SCs complemento podem alternar a ordem Sujeito-Predicado, diferentemente, as SCLs têm uma ordem fixa.

É importante perceber que a discussão acima feita sobre as SCLs, não incidem nas que-SCLs uma vez que, ela não pode aparecer "encaixada" em verbos ECM:

(38) *Eu achei [que lindo o dia]/ [o dia que lindo].

Como já discutido, isso se deve ao fato de constituintes com "que" não poderem aparecer em posições-A no PB.

A seção a seguir tratará os achados empíricos, discutidos até aqui, de forma teórica.

\section{SCL como TP raiz e que-SCL como CP}

\subsection{Sobre as SCLs}

Para Den Dikken (2006), na semântica, a predicação é atribuição de propriedade e, na sintaxe, a predicação envolve uma estrutura assimétrica incluindo o predicado, seu sujeito e um elemento funcional (o RELATOR) mediando a relação configuracional e não-direcional entre o predicado e o sujeito. Por configuracional, entende-se que uma predicação sempre irá conter um RELATOR (R) que é o núcleo da projeção de predicação, RP (Relator Phrase), uma fase inerente. Den Dikken (2006, p.15) assume que o RELATOR é funcional e abstrato, atuando como um placeholder para qualquer núcleo funcional mediante uma relação de predicação entre os dois termos. Adotaremos a estrutura do Relator Phrase, exposta em (39), como a estrutura de uma SC comum:

(39) [ ${ }_{R P}$ Sujeito [RELATOR [Predicado]]] 
Por predicação não-direcional, entende-se uma predicação que pode ocorrer também na ordem linear Predicado-Sujeito, ou seja, com a seguinte configuração: ${ }^{12}$

(40) $\left[_{R P}\right.$ Predicado [RELATOR [Sujeito]]]

Adotando uma configuração RP não-direcional para as SCs e tendo os resultados dos testes aplicados na seção anterior, chegamos à estrutura em (41) para as SCLs do PB. Lembramos que essa conclusão foi possível com base nas verificações de que as SCLs do PB: (i) não são resultados do alçamento à esquerda do predicado, nem do deslocamento à direita do sujeito (cf. 3.1.); (ii) têm o status de uma sentença (cf. 3.2.); (iii) estão in situ (cf. 3.3.); e (iv) têm apenas a projeção de $\mathrm{T}(\mathrm{empo})$ na sua estrutura interna (e, claro, RP) (cf. 3.4.).

(41) $\left[_{\mathrm{TP}} \mathrm{T}\left[_{\mathrm{RP}}\right.\right.$ Predicado [RELATOR [Sujeito]]]

Assim, o que os testes da seção anterior sugerem é que as SCLs são TPs raízes, ou seja, sentenças autônomas que não encaixam, nem podem ser encaixadas, nem têm uma projeção CP associada, ou seja, elas são "livres" realmente. Porém, essa ideia vai de encontro ao que é sugerido em Chomsky (2001 e subsequência), cuja proposta é a de que apenas $\mathrm{CP}$ e $v^{*} \mathrm{P}$ sejam considerados fases (pequenos "pedaços" de estruturas que são mandados ciclicamente para Spell-Out durante qualquer derivação sintática). Para sanar esse problema, adotamos a teoria de Den Dikken (2006) de Extensão de Fase. Tal teoria adota a proposta original de Chomsky (1993) de que o movimento de núcleo estende os domínios sintáticos. Desse modo, se o núcleo do RP, RELATOR, se move para um núcleo externo, as dependências da fase são redefinidas por meio de uma operação de Phase Extension, e, então, nenhum problema de localidade surge. Veja que, de acordo com essa teoria, TP pode ser uma fase derivada da subida do núcleo do RP. Vejamos como isso pode ser aplicado às SCLs do PB abaixo (Ф é o limite de uma fase):

12 Para argumentos a favor da SC (RP) configuracional e não-direcional, ver Den Dikken (2006).

(42) a. $\left[_{R P}\left[{ }_{\text {DegP }}\right.\right.$ Muito linda $]\left[_{R^{\prime}} R\left[_{D P}\right.\right.$ Sua roupa $\left.\left.]\right]\right]$

$\Phi$

b. $\left[_{T P} T+R_{i}\left[_{R P}\left[{ }_{\text {DegP }}\right.\right.\right.$ Muito linda] $\left[_{R^{\prime}} t_{\mathrm{i}}\left[_{D P}\right.\right.$ Sua roupa $\left.\left.\left.]\right]\right]\right]$

$\Phi \longleftarrow(\Phi)$ 
Para formar a fase RP, primeiramente, o núcleo $\mathrm{R}$ deve selecionar o sujeito como complemento e posteriormente o predicado como seu especificador. TP entra na derivação e o núcleo de RP, R, é alçado para T. Esse movimento desencadeia a Extensão da Fase de RP até TP, seguindo a proposta de Den Dikken (2006). Assim, como os traços (não-interpretáveis) de Caso do DP sujeito e $\Phi$ de T ainda estariam presentes na derivação, ela fracassaria. Após ocorrer a extensão da fase, sendo T agora o núcleo da fase, outro problema surge: há um DegP interveniente entre T e o DP sujeito e esse DegP tem traços- $\Phi_{,}^{13}$ que "barrariam" a sonda $\mathrm{T}$ de ir "mais abaixo" (até o DP, nesse caso) para checar seus traços- $\Phi$ e os traços de Caso do sujeito. Adotando o Princípio de Maximização (Maximization Principle), de Chomsky (2001, p. 15), isso deixa de ser um problema, pois, de acordo com esse princípio, um elemento contendo um conjunto de traços- $\Phi$ defectivos ${ }^{14}$ não conta para efeitos de intervenção e, uma vez que um sintagma de grau não tem o traço não-interpretável de [pessoa], a sonda $\mathrm{T}$ pode "pular" esse sintagma. Dito de outra forma: como o predicado não tem traço não-interpretável de [pessoa] para ser checado, o probe T pode descer até o DP sujeito e valorar seu traço de Caso, além dos traços- $\Phi$ [-int] de T. O resultado é, então, uma SCL enquanto TP.

\subsection{Sobre as que-SCLs}

Para as que-SCLs do PB, uma análise diferente deve ser empreendida, uma vez que os testes feitos anteriormente nos mostraram comportamentos diferentes, principalmente no que concerne ao seu predicado, como vimos anteriormente.

Assim, assumindo a teoria de Den Dikken (2006) e

${ }^{13}$ É interessante destacar que, antes de T sondar o DP sujeito, Agree entre o DegP predicado e o DP sujeito já deve ter acontecido, a fim de checar os traços não-interpretáveis de DegP. Devido à falta de espaço, não discorremos aqui sobre como isso acontece.

${ }^{14}$ Ou seja, um conjunto- $\Phi$ incompleto, i. e., sem o traço não-interpretável de [pessoa]. levando em consideração os testes realizados, propomos que a estrutura dessas estruturas é aquela em (43):

(43) $\left[_{\mathrm{CP}}\left[{ }_{\mathrm{DegP}} \text { Que linda }\right]_{\mathrm{i}} \mathrm{C}\left[_{\mathrm{TP}}\left[{ }_{\mathrm{DP}} \text { a sua roupa }\right]_{\mathrm{j}} \mathrm{T}+\mathrm{R}_{\mathrm{t}}\left[_{\mathrm{RP}} t_{\mathrm{j}}\left[_{\mathrm{R}^{\prime}} t_{\mathrm{t}} t_{\mathrm{i}}\right]\right]\right]\right]$

Lembremos que (43) foi possível porque vimos que: (i) o sujeito ocupa uma posição-A (cf. 3.1.); (ii) o predicado das queSCLs não pode ocupar uma posição-A (cf. 3.1.); e (iii) tanto o sujeito quanto o predicado das que-SCLs não pode estar abaixo de RP (cf. 3.3.). 
A derivação em (43) ocorre de maneira inversa à (42): a predicação é direcional, assim, $\mathrm{R}$ seleciona um predicado em [Compl, R] e um sujeito em [Spec, RP], logo em seguida, ocorre a checagem de traços não-interpretáveis de gênero e número do predicado, DegP. R é alçado para T, desencadeando a extensão da fase de RP para TP. O sujeito é alçado para [Spec, $\mathrm{TP}$, onde checa Caso nominativo. Por fim, com o propósito de checar seu traço [+wh] não-interpretável, o predicado é alçado para [Spec, CP]. Assim, com todos os traços não-interpretáveis devidamente checados e deletados, a estrutura é enviada para as interfaces.

\section{Considerações finais}

Neste artigo, analisamos os dados do que chamamos aqui de SCLs e que-SCLs, estruturas pouquíssimo estudadas do PB. Na primeira seção, mostramos com base em testes elaborados por Zanuttini e Portner (2003) que ambas as estruturas têm o comportamento de sentenças exclamativas. Na segunda seção, apresentamos algumas restrições sintático-semânticas dos constituintes dessas estruturas e concluímos que os constituintes de ambas as estruturas têm comportamentos semelhantes. Na terceira seção, verificamos que as que-SCLs parecem se diferenciar das SCLs em relação, principalmente, ao seu predicado: enquanto que o predicado das SCLs está numa posição-A, o predicado das que-SCLs parece estar numa posição-A'. Na quarta seção, tomamos os resultados dos testes da terceira seção e, adotando a proposta de SC e de Extensão de Fase de Den Dikken (2006, 2007), propomos que as SCLs são TPs e que as que-SCLs são CPs.

\section{REFERENCIAS}

BARTRA, A.; VILLALBA, X. Non Agreeing Quantified Nominal Embedded Clauses in Spanish. Ms. Universitat Autònoma de Barcelona, 2006.

CARDINALETTI, A.; GUASTI, M. T. Small clauses: Some controversies and issues of acquisition. In: CARDINALETTI, A.; GUASTI, M. T. (Eds.). Syntax and semantics: small clauses. California: Academic Press, v. 28, p. 1-23.1995. 
CASTROVIEJO, E. A degree-based account of Wh-exclamatives in Catalan. Proceedings of Sinn und Bedeutung. Barcelona: Universitat Pompeu Fabra,134-49.2007.

CHOMSKY, N. A minimalist program for linguistic theory. In: HALE, K.; KEYSER, S. J. (Eds.). The view from building 20. Cambridge, Mass.: MIT Press, 1993. p. 1-52.

CHOMSKY, N. Derivation by phase. In: KENSTOWICZ, M. (Ed.). Ken Hale: a life in language. Cambridge, Mass: MIT Press, 2001. p. 1-52.

DIKKEN, M. den. Predicate Inversion in DP. In: ALEXIADOU, A.; WILDER, C. (Eds.). Possessors, Predicates and Movement in the Determiner Phrase. Amsterdan: John Benjamins, 1998. pp. 177-214.

DIKKEN, M. den. Relators and linkers: the syntax of predication, predicate inversion, and copulas. Cambridge, Mass.: The MIT Press, 2006.

DIKKEN, Marcel den. Phase extension: Contours of a theory of the role of head movement in phrasal extraction. Theoretical Linguistics 33(1), p. 1-41. 2007.

ELLIOTT, D. E. Toward a Grammar of Exclamations. Foundations of Language, 11, p. 231-246. 1974.

GUTIÉRREZ-REXACH, J. Spanish root exclamatives at the syntax/semantics interface. Catalan Journal of Linguistics, n. 7, p. 117-133, 2008.

KATO, M. A. Free and dependent small clauses in Brazilian Portuguese. Handout apresentado no GT de Teoria da Gramática, 1988.

MARANTZ, A. On the Nature of Grammatical Relations. Cambridge, MA: MIT, 1984.

RIZZI, L. The Fine Structure of the Left Periphery. In: HAEGEMAN, L. (Ed.). Elements of Grammar. Dordrecht: Kluwer, 1997, p. 281-337.

SPORTICHE, D. A Theory of Floating Quantifiers and Its Corollaries for Constituent Structure. Linguistic Inquiry, v. 19, n. 3, p. 425-449.1988.

VILLALBA, X. Exclamatives and Negation. Ms. UAB, 2004. 
ZANUTTINI, R. Syntactic properties of sentential negation. Ph.D. Dissertation: University of Pennsylvania, 1991.

ZANUTTINI, R.; PORTNER, P. Exclamative clauses: at the syntax-semantics interface. Language v. 79, n. 1, p. 39-81, 2003.

\begin{abstract}
Similarities and differences between two exclamative sentences of Brazilian Portuguese
\end{abstract}

In a descriptive side, this paper aims to observe the syntactic-semantic pattern of two exclamative structures under-researched of Brazilian Portuguese and, through some diagnostics, verify the differences and similarities between them. In a theoretic side, taking into account the results of these tests, we verify how this structures are derived, adopting as conceptual framework the Generative Grammar, in Minimalist Program model (CHOMSKY, 2001 and henceforth). Then, after presentation, discussion, and theoretical analysis of data of these exclamative structures, we attest that they have distinct structures: while one behaves like a Tense Phrase (TP) the other behaves like a Complementizer Phrase (CP).

Keywords: Syntax; exclamatives; Brazilian Portuguese. 